\title{
Academic Dean and the Challenges of Meeting Changing Expectations within a Competitive Higher Education Environment in Africa
}

\author{
Alfred Otara \\ College of Education, University of Rwanda, Kigali, Rwanda \\ Email: Fredcoco2003@yahoo.co.uk \\ Received 14 January 2015; accepted 2 February 2015; published 5 February 2015 \\ Copyright (C) 2015 by author and Scientific Research Publishing Inc. \\ This work is licensed under the Creative Commons Attribution International License (CC BY). \\ http://creativecommons.org/licenses/by/4.0/ \\ (c) (i) Open Access
}

\begin{abstract}
This article looks at the challenges involved and seeks to provide guidelines for leadership decisions and practices for the Deans that can be effective in institutions of higher learning. This paper provides an overview of academic leadership by faculty deans, and assesses the degree to which deans exhibit the behaviors embedded in this leadership in addressing the challenges and expectations of this century. Deanship is therefore treated as the academic act of building programs and a community of scholars to set direction and achieve the expectations of stakeholders in the current challenging economic times. The need for transformational leadership is emphasized. The paper shows how academic leaders must be the purveyors of ideas and knowledge that shape managerial thought and practice. Further, academic leadership needs to develop a human resource network inside and outside the departments and university and at the local, national, and international levels. Academic leadership needs to have a clarified program for faculty and staff promotion and development, and it should be placed on a priority list and agenda. Deans will need to use technology effectively and communication innovations to improve access to knowledge. Keeping pace with change in the world of work means offering education programmes that are relevant, are of high quality and, increasingly, include practical or work experience, as well as working more closely with stakeholders such as employers in course design or delivery. They will also need significantly to streamline their operations by incorporating new teaching and learning delivery mechanisms. Finally it is observed that academic leaders should take the initiative by adopting measures of success that are truly useful management tools for their institutions and that have credibility with the institution's external stakeholders.
\end{abstract}

\section{Keywords}

Higher Education, Challenges, Academic Leadership, Innovation, Quality, Change 


\section{Introduction}

Higher education is undergoing a paradigm shift. This historically low competition industry is suddenly turning highly competitive. Collis (1999) of Yale University suggests that a number of drivers of change in higher education include: new technologies, particularly the Internet, a change in the nature of the employment contract from lifetime employment, cost increases that outstrip productivity growth and so lead to a continuing rise in the real price of education, exponential increase in the rate of accumulation of knowledge and the consequent fragmentation and specialization of academia, globalization of academic and education markets, and new competitors entering the business, both as stand-alone institutions and as companies training their own.

Deans juggle multiple roles and a myriad of expectations from diverse constituents. Squeezed from above and below as well as from inside and outside the university, deans are caught in the jaws of conflicting cultures, pressures and priorities. Constrained by traditions and tensions inherent in the role, they are increasingly accountable for outcomes over which they have little influence and less control (Gallos, 2011). The Dean of the Faculty is a senior member of the University's academic administration and is directly responsible for the recruitment, retention, and development of University faculty. The dean oversees departments and programs in the divisions within college or university. The Dean of the Faculty has a significant impact on the University's intellectual life and academic future through hiring decisions, faculty support, and strategic initiative. The dean supervises and approves all faculty searches and departmental hiring plans; works with university governance committees in hiring, reappointment, promotion and tenure. The dean convenes small discussion groups of department chairs and faculty on academic issues and initiatives; serves as the faculty's advocate within the University. Criteria of appointment to the dean's position vary from county to county and even from one university to another. Means that are used include election, direct appointment and even through competitive interview. In respect to qualification one mast be of the rank of senior lecturer and above with leadership qualities. Deans are, in essence, classic middle managers: They have enormous responsibilities, little positional power, insufficient resources and limited authority.

Effective leadership in any organization is a crucial component of overall organizational success. While many aspects of management and leadership are common to most organizations, colleges and universities present special challenges in both their fundamental character and in practice. The presence of faculty and non-academic personnel in leadership roles in the same organization can create ambiguity and confusion. This is particularly an issue when units of the institution seek to achieve the highest possible level of performance, cooperation and mutual trust among and between them (Rowley \& Sherman, 2003).

A study carried out by Wolverton and Gmelch (2002) established that there are three activities deans must perform to lead effectively: building a community of scholars; setting direction; and empowering others. Overall, deans were found to be balanced in their approaches to leadership, with deans in comprehensive universities more likely to describe themselves as community builders than deans in research universities. It was further revealed that after about year 10, deans tend to disengage in direction setting behavior, a finding that may have implications for institutional development.

The academic deanship is the least studied and most misunderstood position in the academy. The work of administration and the pursuit of scholarly endeavors results in paradoxical situation causing many academic leaders to burn out from the strain of trying to be effective administrators, on the one hand, and attempting to protect the academic autonomy and independence of faculty on the other (Gmelch, Wolverton, \& Marvin, 1999). Much of the work of colleges and universities gets done at the academic departmental and faculty level. Yet, most institutions of higher learning pay little attention to either the preparation of academic department leaders or their succession into the position or even the enormous significant works that Deans do.

Deans usually come to their positions without leadership training, without prior executive experience, without a clear understanding of the ambiguity of their new roles, without recognition of the metamorphic changes that occur, and without an awareness of the toll their new position may take on their academic and personal lives. In spite of all these the deans are expected to steer the academic leadership and offer direction to both students and lecturers to their satisfaction. They are therefore expected to promote scholarship, protect higher learning from stagnation and interference, and provide a sound basis for hiring and advancing faculty in meeting the demands of the economy. In light of this scenario there should exist operating alternatives to conventional way of thinking and running faculties (Gmelch, 2000).

The current wind of change in Africa that is coupled with overpopulation and high rate of unemployment is making stake holders to turn their figure and question the quality of education in higher institutions of learning. 
This is a big challenge to the deans. Up skilling is not just something that allows people to get a better job: it is also what enables them to shape the jobs of the future, and thus to actively contribute to an innovative economy (Waters, 2012). So we need not just quantity-we need quality too and for graduates to leave higher education with relevant qualifications and transversal and transferrable skills.

Deans in Universities and higher education institutions need to be flexible, to specialize and to unlock potential of those they lead in order to address the challenges of the $21^{\text {st }}$ century .They are expected to offer transformational leadership that focuses on:

- Improving the quality and relevance of education programmes to increase graduate employability and to meet the demand for people with high-end skills. This stresses the importance of adapting programmes so that each graduate, whatever their discipline, has a good mix of sector-specific and cross-cutting skills to enable them to thrive in a labour market.

- Improving quality and raising skills through mobility and removing the obstacles that hinder mobility.

- Encouraging higher education institutions to develop a stronger role in supporting sustainable growth in their regions and beyond.

\section{Theoretical Framework}

The present study uses the theoretical framework of transformational leadership to understand the behaviors and practices by which Deans mentor lecturers, influence students and develop programs, monitor quality and initiate innovation with an aim of addressing future challenges. Sometimes lecturers may not consciously be aware of their transformational leadership qualities, but their behaviors in the classroom are similar to those same tenets of transformational leadership. An example of transformational leadership could be a Dean who attempts to stimulate and inspire lecturers and students to accomplish great things and develop their own capabilities required to manage prospective challenges. Transformational leaders seek to challenge the process and practice. They accept and embrace challenging opportunities that direct others to greatness.

Transformational leadership occurs when leaders broaden and elevate the interests of their employees, when they generate awareness and acceptance of the purposes and mission of the group, and when they stir their employees to look beyond their own self-interest for the good of the group (Bass, 1990). Deans should demonstrate transformational leadership behaviors empower teachers to rise above their personal expectations and help create and encourage belief in common goals. According to Bandura (1993), the stronger the faculty's shared beliefs in their instructional efficacy, the better the students performed academically. High levels of perceived collective efficacy are associated with a robust sense of purpose that helps groups see setbacks as temporary obstacles to be overcome rather than evidence confirming their inefficacy (Goddard \& Skrla, 2006). Agreeing with these views Ross and Gray (2006), argue that transformational leadership contribute to collective efficacy of lecturers by setting feasible goals, clarifying standards, developing a collaborative school culture, and linking actions of lecturers to student outcomes, a principal influences.

A leader can make a significant impact on the product of the organization. He or she can improve the educational and research infrastructure, and thereby improve the products of these efforts. Deans can foster development of faculty, staff and students to improve the quality of work as well as morale. Improving the quality of education and student mentoring can result in higher student retention and more successful graduates, which is a key factor in how Deans are judged. Deans can also be catalyst for organizational change. If you have something special to bring to your unit including improving diversity, increasing the focus on teaching and learning, developing centers, or increasing interdisciplinary work, leadership provides an opportunity and resources for effecting such changes. Transformational leaders passionately believe that they can make a difference by envisioning the future and creating an ideal and unique image of what universities can become (Kouzes \& Posner, 2002).

\section{Academic Leadership}

Deans as academic leaders exercise their leadership within settings that have markedly different institutional purposes, cultures and expectations than the organizations in which business leaders typically exercise their leadership. Leadership operates within the framework of purpose: vision, shared values, and common cause. The leader does not have to create the vision, but there must be one, and it must be shared by others who willingly commit themselves in common cause (Diamond, 2000). Scott Cowen, President of Tulane University, laments 
the decline of the academy as the largely unchallenged bastion of intellectual leadership: "As academic leaders, we must be the purveyors of ideas and knowledge that shape managerial thought and practice". Executives and organizations should be looking to universities and their faculties to provide the direction and knowledge necessary for organizations to adapt to the changes they are undergoing. All too often, however, we have been looking to industry to give us direction rather than vice versa. Deans therefore must reclaim the intellectual edge if they are to demonstrate continued leadership in the learning domain and provide value to the students and the organizations they seek to serve.

Leadership is thus crucial if faculties have to make a change in this century as Bennis (1985) puts it in Leaders: The strategies for taking charge, "business short of capital can borrow money, and one with a poor location can move. But, a business short on leadership has little chance for survival.” Brown (2011) suggests that advocacy and leadership bring about genuine change by using evidence-based practice and current research to convince people of the value of the changes you want to make and to make sure that the changes you are making align fully with the institution's overall ambitions. In showing transformational leadership in universities Deans are expected to keep abreast of national and international developments in assessment, learning and teaching, prioritizing innovations and good ideas that form the context in which they are working and also to model good practice in their own teaching and assessment.

Programme leaders hold a pivotal role in universities in ensuring that strategic imperatives are translated into action rather than being rhetorical ambitions. Deans as senior managers should work closely with programme leaders. This can be a very powerful partnership that can bring about real change in universities (Brown \& Denton, 2009). Effective academic leadership needs to utilize communication skills, organizational culture, and shared values in order to fulfil mutual trust. Consequently, the interests of faculties, staffs, and leaders converge toward common organizational aims. Leaders should not only direct reciprocal communication, but also provide an effective communication network inside and outside universities. Mutual trust and respect provide an appropriate context and move the organization toward individual and collective goal attainments. Academic leadership should be transformational and collaborative, emphasizing participation, delegation, and teamwork. Driven by the dynamic nature of the academic environment, recommendations for acceptable management based upon an increased utilization of teams and workgroups with multidisciplinary collaboration at local, regional, and international levels should offer a decreased reliance on traditional authority arrangements.

\section{Faculty Development}

Leadership is about evoking high individual performance in others and if effectively exercised, it will result in a team of people who enjoy clear purpose, shared values, who are empowered by knowing that their initiatives are aligned with and supported by team members, and who believe that there is mutual benefit deriving from their individual commitments in turning their common vision into reality (Diamond, 2000). In order to succeed at new teaching, research, and leadership tasks, faculty development is essential (Bikmoradi, 2008). "Management is about human beings. Its task is to make people capable of joint performance-to make their strengths effective and their weaknesses irrelevant” Says (Drucker, 2011).

Successful organizations tap into individuals' intrinsic motivation, thereby enabling a self-sustainable commitment to quality and continuing improvement. The idea is to foster initiative, leadership and accountability throughout the organization - leadership that does not depend wholly on organizational position and formally designated authority. Deming strongly debunks reliance on extrinsic motivators-reward and punishment, fear and incentives-as short-term, no sustainable practices that rob people of their self-esteem and dignity. Although we believe that extrinsic motivators do influence behavior, we see them as only one component of many structural elements that must continuously be aligned with mission (Diamond, 2000).

"When an institution, organization or nation loses its capacity to invoke high individual performance, its great days are over" - John W. Gardner Excellence

Academic work is facilitated through inspired and shared clear vision, goals, and strategies, consistently pursued and communicated with integrity, an understanding of individual needs, and energetic commitment. Academic leadership needs to develop a human resource network inside and outside the departments and university and at the local, national, and international levels. These networks could create an effective academic leadership on learning, teaching, and research processes (Bikmoradi, 2008). An effective and efficient reward system with appropriate and on time feedback should be able to improve output of academic work, according to possible results of an efficient evaluation system focusing on staffs, departments, and school performance. Academic lead- 
ership needs to have a clarified program for faculty and staff promotion and development, and it should be placed on a priority list and agenda.

A campus culture that values collegiality and civility is among the most important contributions a university can make. Academic departments recognize the desirability of a collegial environment for faculty members, students, and professional employees and that such an environment should be maintained and strengthened throughout the university. In an environment enhanced by trust, respect, and transparency faculty members can be revivified so that they can play an active and responsible role in academic matters (Cipriano, 2012).

What deans should strive for in the academy is a healthy and respected sharing of ideas and concepts where people feel free to express their divergent and oftentimes conflicting views. In fact, many historians consider this concept to be one of the hallmarks of higher education Facilitating a culture of collegiality can be the synergistic agent of good relationships among members of a department-which all too often is severely missing. In addition deans should make an effort to ensure that academic citizenship is demonstrated through the service that faculty members perform on various types of committees, in their professional organizations, through their uncompensated civic engagement, and through other professional efforts that benefit the community. Furthermore, it is manifested in excellent teaching when faculty members go above and beyond their contractual obligations to act as mentors to their students, and in superior research when they participate in collaborative efforts, scholarship networks, and multi-institutional academic partnerships (Buller, 2010).

\section{Research and Instruction}

Every year, millions of students enter universities and higher education colleges. They are ready to start a new chapter of their lives and hope to acquire the knowledge and skills that will equip them for future careers. Many arrive with fresh memories of the teachers who inspired them to go on to higher education - and the teachers they are about to meet will be just as important for their success. Yet relatively few countries invest systematically in efforts to improve the quality of university teaching. Instead, university excellence is mostly conceived of in terms of research performance, as confirmed by the growing influence of current university rankings, based mainly on research output (Vassiliou \& McAleese, 2012).

Drucker (2011) observes that "the single most important thing to remember about any enterprise is that there are no results inside its walls. The result of a business is a satisfied customer, the result of a hospital is a healed patient, and the result of a school is a student who has learned something and puts it to work ten years later. Inside an enterprise there are only cost centers. Results exist only on the outside”. Education institutions are so focused on getting students in the door that they lose sight of how to prepare young people to succeed in today's tough labour market. "As a matter of fact it looks like Education providers are much more motivated to focus on getting youth onto campus and less focused on how to prepare youth to exit.” (Millar, 2012). Reflecting on this John Dewey an educationist and a philosopher says "One might as well say he has sold, when no one has bought, as to say he has taught when no one has learned".

It is time to re-evaluate the idea of the university in fact if you examine the mission statement of almost any institution of higher education, you'll discover that teaching and research are listed as important but not necessarily related functions of the organization. In other words, relatively few mission statements present learning as a goal achieved through independent inquiry and research; even fewer describe discovery, integration, and application as results actively sought through teaching. Once again, the focus is on the activity rather than the result, and that perspective shapes everything that is familiar about the modern university (Buller, 2012). In almost all universities you will notice that:

- Departments are organized around disciplinary methods (activities) rather than important questions being asked or issues being explored (results).

- Individual courses are defined by "seat time" and contact hours (activities) rather than competencies gained and knowledge developed (results).

- Degrees are granted largely by the number of credits earned (activities) rather than the amount of growth achieved or improvement attained (results).

Chu (2006) says that an academic department should be regarded as an "open system" in which both the stakeholders and beneficiaries are numerous: faculty members, students, alumni, parents of current students, accrediting agencies, prospective employers of graduates, nongovernment organizations, funding agencies, and so on. Re-evaluating the idea of the university will mean approaching it not as a closed system in which professors teach and conduct research, but as an open, organic network that includes a vast system of constituents and 
stakeholders. It is rapidly becoming accepted that there are alternative models for describing how students learn. It should be equally clear that alternative models also exist for describing how universities and university systems produce benefits for society. In what is perhaps the most comprehensive approach to promoting research while advancing instruction to date, Jenkins, Healey, and Zetter (2007) describe six effective strategies that deans can adopt in order to make timely progress in attaining this goal.

1) Work through individual disciplines to develop a clearer understanding of how teaching and research intersect in their own practices and methods.

2) Review areas where current culture seems to inhibit the cross-fertilization between teaching and research, and revise policies where appropriate. Assessment data, student surveys, organizational audits, and comprehensive program reviews can all provide helpful information in this regard.

3) Develop an institution-wide set of curricular goals for promoting research among all students, even at the undergraduate level.

4) Modify staffing policies so that future hires are likely to support the full integration of teaching and research.

5) Revise strategic planning goals and categories so that teaching objectives and research objectives better support one another.

6) Incorporate a fully integrated approach toward teaching and research into institutional culture. For instance, incorporate assessment of research knowledge into curricular assessment, encourage research clusters to become teaching teams, and give research wide visibility to students at all levels of the institution.

Deans could properly consider "high impact learning" which comes from Kuh, Kinzie, Schuh and Whitt (2005)'s work with NSSE [National Survey of Student Engagement]. They are particularly beneficial for students in terms of academic and personal growth, career development, and a wide range of desired learning outcomes (Kelly, 2012). There's something unique about high impact learning. It seems to have a greater impact than what we're used to. The type of learning tends to be very intense, not simply students walking into a lecture hall and hearing a lecture but students being required to learn on multiple levels. They're creating new knowledge, implementing it in real-life settings, and reflecting on the implications for themselves and the community.

It said that "transversal skills such as the ability to think critically take initiative, problem-solve and work collaboratively will prepare individuals for today's varied and unpredictable career paths”. It is "teaching that primarily influences student outcomes, enhances graduate employability and raises the profile of African higher education institutions worldwide; this should be the core business of the deans. Learning at the postsecondary level includes not only the knowledge and skills that students gain from their formal course work but also the discoveries they make through their independent research. In other words, the revolution begun by Robert Barr and John Tagg (1995) has changed the way we look at what students do at a college or university, so why do we still insist on looking at teaching, research, and service as separate activities, rather than evaluating the learning that results from all three?

\section{Programs}

Many challenges confront universities and to thrive, or even to just survive amid these challenges, requires that the academic unit be continuously aligned with the changing needs of the constituencies that it serves: its students, alumni, employers, its university, and the larger academy (Diamond, 2000). No academic unit can be successful for long if it isolates itself from knowledge of its constituencies' changing needs or fails to maintain value-adding relevance within its scholarship, education programs and services. Escalating demands for change and accountability reflect growing dissatisfaction with the way university graduates are prepared for the challenges and continuing development that will characterize their lives and their professional careers. There are vigorous calls for innovation in curriculum, learning methods and education program delivery and this should be the concern of deans if they have to excel as academic leaders.

"Statistics in universities suggest that the share of the working population with a degree or above is going to increase, so we not only need to ensure we're producing more graduates but also that the graduates we produce have the competences and skills which are in demand,” (Dennis Abbott as quoted by Osborn, 2012). People will need to move around more and that's one reason why we say we need to produce graduates who are much more versatile. African universities must align more closely with labour market needs to ensure graduates have the skills and knowledge demanded by employers. "In the continent higher education is expanding rapidly and when you expand so rapidly misalignment between higher education and the labour market grows” (Sharma, 2012). 
Higher education systems and institutions are under pressure to reform, to provide adequate skills and knowledge for the evolving labour markets. This is increasingly important in countries which are moving towards middle-income country status and aspiring to become knowledge economies, increasing the demand for higher skills. The problem is that the workplace is no longer a stable, hierarchical structure. So the most important skill in the 21st century is adaptability. The current scenario is that universities are not accustomed to taking responsibility for employability. That stance is rapidly changing and universities must get ahead of the curve, deans must elevate employability to an issue for students to consider in their first year of study. Empowering and preparing citizens for a greater role in development and innovation should remain the main purpose of faculties. Deans must enter into collaboration with industry, the private sector and the civil society to improve labour market links in enhancing training programs.

If we want to ensure that everyone who can go into higher education does so, and that our universities equip their students with the right skills, we need change-we need a change of culture. Curricula must meet the needs of a diverse student body and provide skills that are sought after by employers (Vassiliou \& McAleese, 2012). Universities need to use technology effectively and communication innovations to improve access to knowledge. Keeping pace with change in the world of work means offering education programmes that are relevant, are of high quality and, increasingly, include practical or work experience, as well as working more closely with stakeholders such as employers in course design or delivery.

\section{Innovation}

Albert Einstein once observed, "The world that we have made, as a result of the level of thinking we have done thus far, creates problems that we cannot solve at the same level of thinking we were at when we created them". African universities have not adequately prioritized innovation and creativity as an important learning outcome. Policymakers and educators need to do more to build faculties' capacity to compete and innovate by investing in critical skill sets and basic research. Institutions as well as government agencies have failed to sustain and nurture innovation in our colleges and universities. Results of scholarly research on teaching and learning are rarely translated into practice, especially for those working at the grassroots level in fields such as teacher preparation and math and science education.

If universities were re-structured according to interdisciplinary emphases and topics, we would foster innovation more efficiently: At a time when innovation occurs increasingly at the intersection of multiple disciplines (including business and social sciences), curricula and research funding remain largely contained in individual departments. At present the standard division of faculty labor into three categories of activity-teaching, research, and service-is so common that most academics regard it as fundamental to the very way in which higher education works (Buller, 2012). The fact is that broadening the definition of scholarship and recognizing that important learning takes place all throughout the university, while important first steps, simply don't go far enough in helping institutions address what faculty members actually do in their work today.

Innovation may be observed when faculty members discover and apply new knowledge, develop or perform creative works, and engage in entrepreneurial activities either in their discipline or in service to the institution. In addition, innovation may be regarded as including educational improvements that lead to enhanced student learning, original ways of serving their community or profession, and programmatic advances that make a college or university more distinctive.

Universities will not survive the next 10 to 15 years unless they radically overhaul their current business models. Maslen (2012) observes that a challenging report released by international professional services company Ernst \& Young, claims that the current university model Vassiliou a broad-based teaching and research institution with a large base of assets and back office Vassiliou will prove unviable in all but a few cases. Academic deans will need significantly to streamline their operations by incorporating new teaching and learning delivery mechanisms, "a diffusion of channels to market, and stakeholder expectations for increased impact". The report identifies the main drivers of change it says will inevitably bring about a transformation of higher education. These are:

- The democratization of knowledge as a consequence of massive expansion of online resources.

- The contestability of markets and funding as a direct consequence of declining public investment and the adoption of market design policies to fund and regulate higher education.

- Digital technologies changing the way courses are delivered.

- Global mobility of students and staff. 
- Integration with industry to differentiate programmes (through work-integrated learning) and to support and fund applied research.

"Current university models are living on borrowed time" observes Maslen; government funding is tight and is going to be tighter still in the next couple of political cycles. While they are not exactly businesses, they will have to run like businesses. They need to be lean and mean. Deans should critically assess the viability of their institution's current business model, develop a vision of what a future model might look like, and develop a broad transition plan. Academic units must choose 1) which market segments their graduates will target; 2) what the nature of their programs will be (undergraduate, MBA, specialized master's, Ph.D.); 3) what competencies they will focus on (leadership, technology, systems expertise, international); and 4) what learning methodologies (lecture, experiential, distance, cooperative, service) they will employ. Making choices like these will enable the academic unit to focus its always scarce resources in recruitment and deployment of faculty, in the development of learning processes, in the application of technology, and in building alliances both with external constituencies and within its university (Diamond, 2000).

"Strategy implementation is more about commitment than correctness. An excellent strategy with adequate implementation will always lose to an adequate strategy with excellent implementation".-Michael Davidson The Transformation of Management

\section{Quality}

Sawahel (2012) says that while quality assurance is developing rapidly in African higher education, it is still at a formative stage in many countries, and only 19 out of 55 states have a national quality agency, according to a report just published by the European University Association. Some long-standing academic leaders may remember that once-upon-a-time when universities enjoyed a highly honored status in the society, a time when society intuitively embraced the academy's mission and supported it generously, largely without questioning what went on within the closed walls (Diamond, 2000). As the challenges of this century begin to bite, many in higher education view themselves as under siege., higher education's relevance in preparing individuals for living a life and earning a living in society is being challenged.

The quality of teaching in higher education institutions is key to unlocking the full potential of students and creating a healthy economy and society. High caliber teachers, and the institutions and systems that support them, clearly impact on these challenges. Its starting point is that higher education is ever more crucial in creating and sharing the high-end knowledge and skills Africa needs. Excellent higher education is a source of competitive economic advantage and, at a time of crisis, a key to sustainable economic recovery (Vassiliou \& McAleese, 2012). Higher education is also a major driver of social progress as it trains graduates to respond creatively to challenges. At the same time, competition between universities increases as the quality of higher education improves around the globe. The knowledge economy means that the nature of jobs will change dramatically and that graduates will need constantly to update their knowledge and acquire new skills.

Universities are experiencing growing expectations and increased accountability for the outcomes they produce, i.e., credible evidence that their students are learning, that their scholarship is relevant and value-adding, and that their service is more than just time spent, but actually produces results that are beneficial to the institution's stakeholders:

- The clamor for accountability is loudly heard in public policy arenas and in decisions, from trustees having stewardship responsibility for the institution's effectiveness, and from individual, business and foundation donors who underwrite a substantial portion of the university's costs.

- Paying customers, i.e., students, parents and employers, are increasingly looking for outcome measures, comparative statistics and assessments that will inform their decisions about where to buy.

- Accreditation processes, peer rankings and media rankings send universities scrambling to compile credible evidence of their comparative worthiness in the competition for recognition and respectability.

There are substantial risks for the university that finds its measures of success being dictated solely by the pressure to satisfy these external demands for outcomes measurement (Diamond, 2000). First, there is the risk that the success measures may be driven by fickle, changing sets of priorities from ever changing sets of stakeholders, and thereby become unfocused, unconnected, and possibly even inconsistent, with the specific mission of the university. Second, there is the risk that the university's chosen measures will be focused on outcomes alone, and may largely ignore the drivers of those outcomes (the essential core processes of the university).

Academic leaders should take the initiative by adopting measures of success that are truly useful management 
tools for their institutions and that have credibility with the institution's external stakeholders-measures that genuinely inform decisions about enrollments, faculty hiring and development, program and curriculum development, and resource allocations (Diamond, 2000). Given the complexity of the academic enterprise, and the diversity of its customers and stakeholders, multiple sets of measures are required. These measurement sets may be quantitative, including monetary and statistical data, qualitative, including peer review and customer/stakeholder judgments, and/or comparative, including benchmarking against peers and tracking performance results over time.

\section{Conclusions}

The current challenges require deans to do things differently, shedding smaller and inefficient activities and concentrating on more strategic initiatives in their leadership through helping institutions to modernize their educational offerings and their ways of working, and specific Knowledge Alliances between higher education institutions and businesses, promoting innovations in designing new curricula and qualifications and fostering creativity and entrepreneurship.

In addressing the challenges of the $21^{\text {st }}$ century Deans will have to show willingness to challenge the system in order to turn ideas into actions and to get new products, processes, and services adopted. They should seek out challenging opportunities that test their skills and abilities and look for innovative ways to improve their organizations in readiness for the future. Transformational leaders are therefore willing to change the status quo (Abu-Tineh, Khasawneh, \& Omary 2009). Deans must reclaim the intellectual edge if they want to demonstrate continued leadership in the learning domain and provide value for the students and the organizations they seek to serve.

\section{References}

Abu-Tineh, A. M., Khasawneh, S. A., \& Omary, A. (2009). Kouzes and Posner's Transformational Leadership Model in Practice: The Case of Jordanian Schools. Journal of Leadership Education, 7.

Bandura, A. (1993). Perceived Self-Efficacy in Cognitive Development and Functioning. Educational Psychologist, 28, 117148. http://dx.doi.org/10.1207/s15326985ep2802_3

Barr, R. B., \& Tagg, J. (1995). From Teaching to Learning: A New Paradigm for Undergraduate Education. Change. 27, 1255. http://dx.doi.org/10.1080/00091383.1995.10544672

Bass, B. M. (1990). From Transactional to transformational Leadership: Learning to Share the Vision. Organizational Dynamics, 18, 19-31. http://dx.doi.org/10.1016/0090-2616(90)90061-S

Bennis, W. (1985). The strategies for Taking Charge. http://www.amazon.com/Leaders-The-Strategies-Taking-Charge/dp/006015246X

Bikmoradi et al. (2008) Requirements for Effective Academic Leadership in Iran: A Nominal Group Technique Exercise. http://creativecommons.org/licenses/by/2.0

Brown, S. (2011) Bringing about Positive Change in the Higher Education Student Experience: A Case Study. Quality Assurance in Education, 19, 195-207. http://dx.doi.org/10.1108/09684881111158027

Brown, S., \& Denton, S. (2009) Leading the University beyond Bureaucracy. In S. Denton, \& S. Brown (Eds.) Beyond Bureaucracy: Managing the University Year. London: Routledge

Buller, J. (2012). Promoting Research While Advancing Instruction, Part 1. Academic Leader, $27,7$.

Buller, J. L. (2010). The Essential College Professor: A Practical Guide to an Academic Career. San Francisco, CA: Jossey-Bass.

Chu, D. (2006). The Department Chair Primer: Leading and Managing Academic Departments. Bolton, MA: Anker.

Cipriano, R. E. (2012). Faculty Collegiality as a Synergistic Agent. http://www.facultyfocus.com/articles/academic-leadership/faculty-collegiality-as-a-synergis

Collis, D. (1999). When Industries Change: Scenarios for Higher Education. https://net.educause.edu/ir/library/pdf/ffp0006.pdf

Diamond, M. A. (2000). Academic Leadership: Turning Vision into Reality. London: The Ernst and Young Foundation.

Drucker, P. (2011). People and Performance. New York: Routledge.

Gallos, J. V. (2011). The Dean's Squeeze: The Myths and Realities of Academic Leadership in the Middle. Journal of Leadership and Organizational Studies, 18, 293-307. 
Gmelch, W. H., Wolverton, M., Wolverton, M. L., \& Sarros, J. C. (1999). The Academic Dean: An Imperiled Species Searching for Balance. Research in Higher Education, 40, 717-740. http://dx.doi.org/10.1023/A:1018717015528

Goddard, R., \& Skrla, L. (2006). The Influence of School Composition on Teacher Perceptions of Collective Efficacy. Educational Administration Quarterly, 42, 216-235. http://dx.doi.org/10.1177/0013161X05285984

Jenkins, A., Zetter, R., \& Healey, M. J. (2007). Linking Teaching and Research in Disciplines and Departments. Heslington: Higher Educational Academy. http://www.facultyfocus.com/articles/academic-leadership/promoting-research-while-advancing

Kelly, R. (2012). Implementing High-Impact Learning across the Institution. Academic Leader, 27, 7-8.

Kouzes, J. M., \& Posner, B. J. (2002). Leadership Challenges (3rd ed.). San Francisco, CA: Jossey-Bass.

Kuh, G., Kinzie, J., Schuh, J., \& Whitt, E. (2005). Student Success in College Creating Conditions That Matter. Washington DC: Jossey-Bass.

Maslen, G. (2012). Universities Face Uncertain Future without Radical Overhaul. University World News, No: 245.

Millar, E. (2012). Universities Need Private Sector to Help Prepare Students for Work. University World News, No: 248.

Osborn, A. (2012). Rethinking Education’ Calls for More Business Focus. University World News, No: 249.

Ross, J. A., \& Gray, P. (2006). Transformational Leadership and Teacher Commitment to Organizational Values: The Mediating Effects of Collective Teacher Efficacy. School Effectiveness and School Improvement, 17, 179-199. http://dx.doi.org/10.1080/09243450600565795

Rowley, J., \& Sherman, H. (2003). The Special Challenges of Academic Leadership. Management Decision, 41, $1058-1063$. http://dx.doi.org/10.1108/00251740310509580

Sawahel, W. (2012). Quality Assurance on the Rise, but More Action Needed-Report. University World News, No: 245.

Sharma, Y. (2012). Universities Must Better Prepare Young People for Labour Market. University World News, No: 250.

Vassiliou, A., \& McAleese, M. (2012). European Commission-Bringing Teaching in from the Cold. University World News, No: 241.

Waters, M. (2012). Leadership Succession: How New Deans Take Charge and Learn the Job. University World News, No. 243.

Wolverton, M., \& Gmelch, W. H. (2002). Adapted from College Deans: Learning from Within. The Annual Meeting of the American Educational Research Association. Newyork: Oryx/Greenwood Press. 
Scientific Research Publishing (SCIRP) is one of the largest Open Access journal publishers. It is currently publishing more than 200 open access, online, peer-reviewed journals covering a wide range of academic disciplines. SCIRP serves the worldwide academic communities and contributes to the progress and application of science with its publication.

Other selected journals from SCIRP are listed as below. Submit your manuscript to us via either submit@scirp.org or Online Submission Portal.
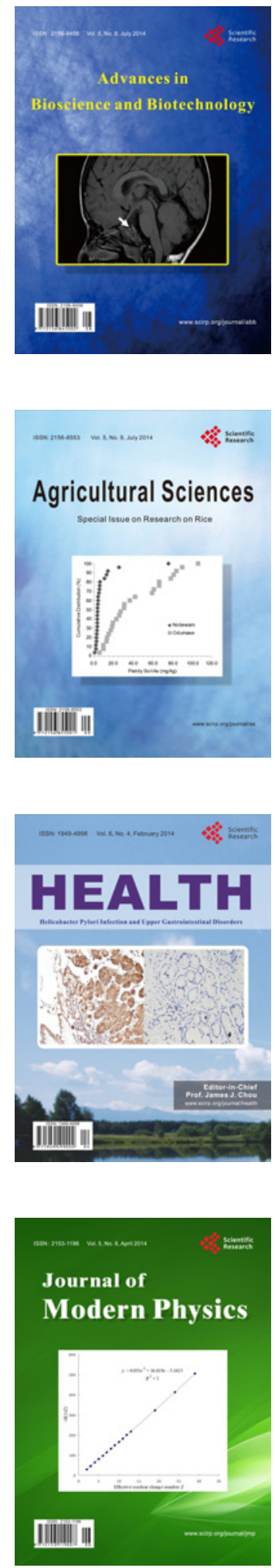
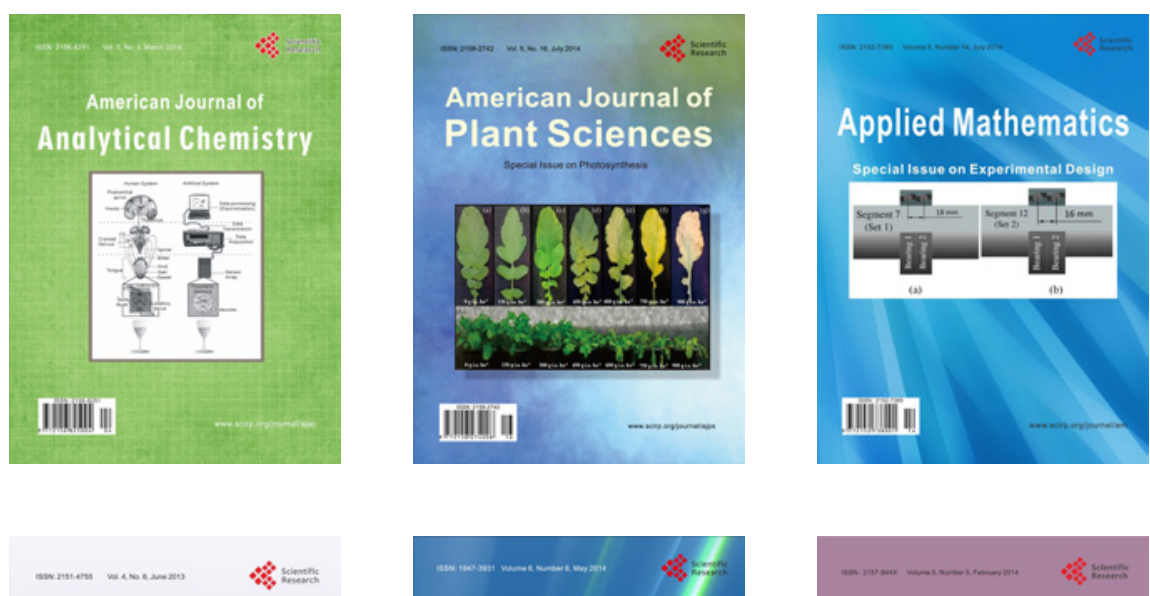

Creative Education
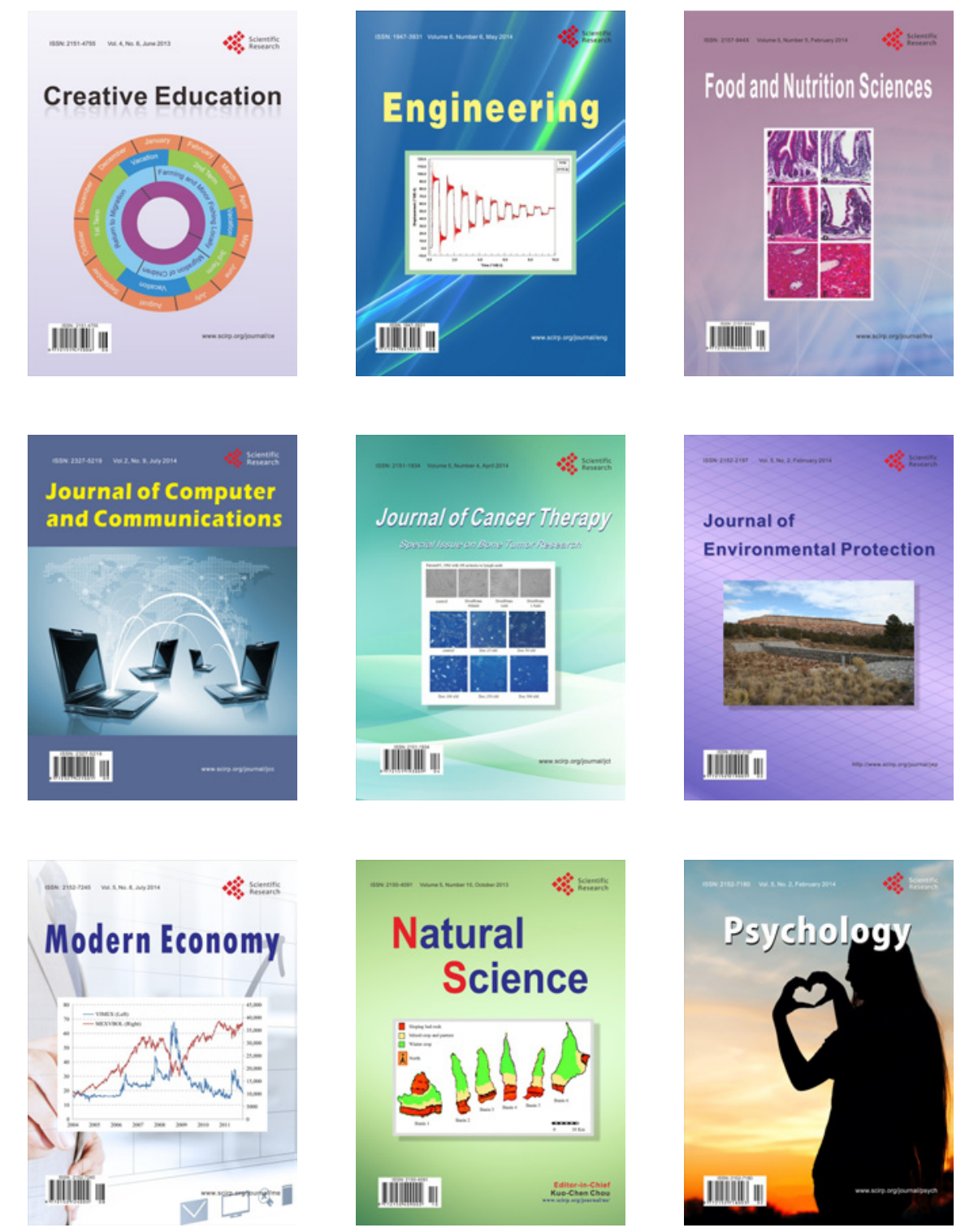